\title{
Study of Oviposition Pattern and Clutch Traits in a White Leghorn (WL) Layer Population
}

\author{
B.G. Roy ${ }^{1 *}$, M.C.Kataria ${ }^{2}$ and U. Roy ${ }^{3}$ \\ ${ }^{1}$ Institute of Nuclear Medicine and Allied Sciences, Brig. SK Mazumdar Road,Timarpur, Delhi-110054, India \\ ${ }^{2}$ Division of Avian Genetics and Breeding, Central Avian Research Institute, Izatnagar, Bareilly-243122, India \\ ${ }^{3}$ Central Institute for Research on Goat Farah, Makhdoom, Mathura-281122, India
}

\begin{abstract}
Various layer traits were recorded on 1082 pullets at $29^{\text {th }}$ generation of selection to evaluate the variability for egg production. Oviposition time of each egg was recorded at hourly and half an hour intervals under 16L: $8 D$ cycle, up to 40 weeks of age and for 15 days period respectively, to study the distribution pattern of oviposition time. Early (06-11h) and late (11-17 h) pattern of oviposition, with $90 \%$ of ovipositions occurring before $13 \mathrm{~h}$ of the day was observed. Mean oviposition time (MOT) and mean oviposition interval (MOI) of the flock were $10.99 \mathrm{~h}$ and $24.34 \mathrm{~h}$ at hourly intervals, whereas, $10.70 \mathrm{~h}$ and $24.43 \mathrm{~h}$ at half an hour intervals of recording, respectively. Mean values of clutch length, clutch number, maximum clutch length, total pause days and interval between clutches were found to be 11.10 days, 12.69, 38.15 days, 23.67 days and 2.20 days respectively. Recorded data revealed variable degree of skewness and kurtosis for different traits. Clutch traits revealed more variation than MOT and MOI. The distribution of MOT and MOI showed narrow range and low percentage coefficient of variation than other traits.
\end{abstract}

Key words: Clutch traits, Oviposition time, Layer

\section{Introduction}

Present day WL layers are the results of long generations of selective breeding for traits governed by many genes. Many layer stocks exhibit a plateau situation with regard to rate of egg production (Siegel et al. 2006) due to exhaustion of additive genetic variance in selection criterion (Carlborg et al. 2006). Further gain in egg production is unwarranted because of losing genetic variation of the traditional selection traits and limitation of one egg per day (Luc et al. 1996). Study of oviposition pattern and clutch traits, that represents the laying characteristics of a pullet might help to unravel the extent of variation with in a flock for egg production improvement.

Egg laying is a complex process in which oviposition time, oviposition interval and clutch lengths are inter-related to each other in an intricate ways. In a $24 \mathrm{~h}$ light-dark cycle, egg laying from high yielding strains seldom occur in dark (Patterson 1997). Most of the oviposition occur in very limited part of the day (Lillpers 1991), about 5-6 h after light on (Zakaria et al. 2005), leading to mean oviposition time 13 to $14 \mathrm{~h}$ after onset of darkness (Lillpers 1991, Patterson 1997). Lighting schedule (Lewis et al. 2005), feeding time (Backhouse and Gouse, 2005) and management stress affects oviposition time, apart from the age and genetic background of the flock. The precise relationship between egg production, oviposition time, oviposition interval and clutch traits can only be understood by accurate recording of oviposition in limited part of the day (range is 05 AM to 07 PM) over longer period of production (Patterson 1997). The $24 \mathrm{~h}$ barrier of light-dark cycle is the main reason for mean oviposition interval ranging between 24 to $26 \mathrm{~h}$ (Sheldon et al. 1984). The clutch length reflects the egg production capacity of a hen and shows greater variation in distribution, because of internal ovulation, shellless eggs and soft shelled eggs that disrupts or alter the sequence length (Johnston and Gous, 2007). In actual experimental conditions, more variation in sequence characteristics among individuals in a flock have been reported than the expected one ((Johnston and Gous, 2007).

Few attempts have been made to record the oviposition time (Patterson 1997, Zakaria et al. 2005), oviposition interval (Lillpers and Wilhelmson, 1993, Figueiredo et al. 2000) and clutch traits (Chen-Tixier Biochard, 2003, Johnston and Gous, 2007) for estimation of genetic variance (Lillpers and Wilhelmsom, 1993, Chen-Tixier Biochard, 2003) and their possible use as alternate selection criterion for improvement in egg production (Noda et al.2002 and Chen-Tixier Biochard, 2003).

In view of the above, the present investigation was designed to record various layer traits including oviposition time, oviposition interval and clutch traits in long term selected WL population with the purpose to utilize the observed variations further in combined family index selection study. 


\section{Experimental stock and history}

\section{Materials And Methods}

The IWH strain of WL hens was used for present investigation. This strain has been maintained as a closed flock at experimental layer farm of CARI, Izatnagar, U.P, India since 1972. The experimental strain has undergone intense selection for part period (40 weeks of age) egg production for 22 generation and then 64 week of age egg production till the present $29^{\text {th }}$ generation. The method of selection was combined family index as per Osborne $(1957 \mathrm{a}, \mathrm{b})$. The selected pullets were assigned at random to the selected males with only restriction that no half-sib or full-sib matings were permitted. The strain was reported to have improved by about $72 \%$ for part period egg number till $22^{\text {nd }}$ generation over the base population with average response of 0.99 to 1.25 eggs per generation (Anonymous et al. 2007). The egg weight and age at sexual maturity have declined over the base population by $0.68 \mathrm{gm}$ and 1.04 days per generation along with decline in 40 week body weight (Anonymous et al. 2007). Anonymous et al. (2007) reported that, by observing the very low heritability estimates in principle trait (egg number 40, 64), it seems that long period of selection for egg number might have exhausted the additive genetic variance for egg production and thus there is need to explore the new genetic variability in the existing flock.

\section{Management practices}

The chicks were obtained from hatchery on zero day, pedigreed by sire and dam, placed on floor pens under hover type brooders and were reared there until about 08 weeks of age. All chicks were vaccinated against Ranikhet disese, Merek's disese, Fowl pox, Infectious bursal disease and Egg drop syndrome-76 and viral infections as per routine vaccination schedule. Starter ration was fed from hatching to $8^{\text {th }}$ week, grower ration from $9^{\text {th }}$ to $16^{\text {th }}$ week and layer ration thereafter. Feed and water were given ad libitum. Sexing was done at $8^{\text {th }}$ week and thereafter both the sexes were kept separately in growing pens. At $16^{\text {th }}$ week of age, all the pullets were transferred to the individual laying cages, arranged in a three-tier system under open sided layer house. Lighting schedule in grower house was set to 14 hour light and 10 hour dark cycle (photoperiod; 06.00 to 20.00 $\mathrm{h})$. At the beginning of 14 week, the length of photoperiod was successively increased and from 16 week of age a $16 \mathrm{~L}$ : $8 \mathrm{D}$ light programme was applied, with lights on between 06.00 and $22.00 \mathrm{~h}$. Light intensity at the height of bird's eye was about 30 lux. The management conditions were kept identical as far as possible for all the hatches. The study started when the hens began laying and continued until they reached the age of 40 weeks.

\section{Sample size and recording of traits}

Phenotypic performance of 1216 WL pullets were recorded for various layer traits. Body weight was recorded at the age of 16 week (BW16) and at 40 week (BW40) to the nearest of 10 gm accuracy. Average weight of 05 eggs laid by each pullet at 28 week of age (EW28) and at 40 week (EW40) were recorded to the nearest of $0.1 \mathrm{gm}$ accuracy. The age at sexual maturity (ASM) was calculated for each pullet as the difference between the date of hatch and the date of her first egg laid.

Egg number of each pullet was recorded daily by observing the presence of an egg in individual laying cages at hourly intervals at specific period of the day. EN-1: Number of eggs laid in $24 \mathrm{~h}$ period. EN-2: Number of eggs laid in $06 \mathrm{~h}-11 \mathrm{~h}$ (06 AM-11 PM) period. EN-3: Number of eggs laid in $06 \mathrm{~h}-12 \mathrm{~h}$ (06 AM-12 PM) period. EN-4: number of eggs laid in $11 \mathrm{~h}-13 \mathrm{~h}$ (11 AM- $01 \mathrm{PM})$ period. EN-5: number of eggs in $11 \mathrm{~h}-17 \mathrm{~h}$ (11 AM- 05 PM) period. EN-1 to EN-5 were recorded up to the age of 40 weeks all pullets. The oviposition time for every egg laid in the $06 \mathrm{~h}-17 \mathrm{~h}(06 \mathrm{AM}-05 \mathrm{PM})$ period was noted in the data sheet by examining the laying cages of individual hens in each hourly intervals.

Eggs observed before $6 \mathrm{~h}(06 \mathrm{AM})$ or after $17 \mathrm{~h}(05 \mathrm{PM})$ were treated as the eggs of previous day or this day respectively. For all pullets, these eggs were marked as laid on $6 \mathrm{~h}$ and $17 \mathrm{~h}$ respectively. Examination of cages was carried out twice in each hourly interval with cross checking from front to back of each cage to ensure that no egg was left unseen. At the age of $26-28$ week, for a 15 day period, recording of egg laying was done in 30 minute intervals (half an hour) from $6 \mathrm{~h}-17 \mathrm{~h}$ to further ascertain the nearest correct time of oviposition at peak production period.

Mean oviposition time (MOT) for each pullet was calculated by taking the simple arithmetic mean of oviposition time till 40 week of age (MOT 40) and for 15 days period (MOT 15). Oviposition interval is the time taken by a pullet to lay an egg in a sequence (Clutch). Oviposition interval (in hours) for each egg laid by individual pullet was calculated by subtracting the oviposition time of an egg from her subsequent egg within a sequence. A factor of $24 \mathrm{~h}$ was added in every calculation to arrive at the time taken by pullet to lay an egg. Because of preceding pause day, the oviposition interval for one egg sequences and for first egg in a sequence was incalculable. The mean oviposition interval was calculated till 40 week of age (MOI 40) and for 15 days period (MOI 15) by simple arithmetic mean of oviposition intervals. Clutch length and numbers were determined as per Blake and Ringer (1987). Clutch length is the number of eggs laid on consecutive days, without a pause. One egg sequences were also counted as a clutch. Average clutch length (ACL) for individual pullet was calculated by dividing the total number of eggs laid with the total number of clutches till 40 week of 
age. Total clutch number (TCN) for each pullet was calculated from the data sheet by summing the clutches up to 40 week of age. The longest number of consecutive days in which there were ovipositions from onset of lay to 40 week of age was counted to get the maximum clutch length (MCL) or prime sequence length as described by Pavilidis et al. (2002). Total pause days (TPD) are the number of days when no oviposition was observed in the record of the pullet till 40 week of age. Average interval between clutches (AIC) was calculated by dividing the TPD with TCN. Soft shelled, broken, extremely small and one out of two eggs in a day was not considered for calculation.

\section{Statistical analysis of data}

As the chicks were obtained in more than one hatch, the data was corrected for significant hatch effects using mixed model least squares and maximum likehood (LSMLMW) as per Harvey (1990). Only the hatch corrected data was utilized in further analysis. Mean, standard deviation (SD), standard error (SE) and coefficient of variation (CV) was calculated by LSMLMW, model IV (Harvey, 1990). Data was checked for skewness, kurtosis, median and range by using Microsoft statistical package (Microsoft office Excel, 2007). Though, varying degree of departure from normality was evident in traits, no transformations were applied. Frequency distributions were calculated for egg number, oviposition time and clutch lengths to study the distribution pattern of pullets in respective traits using Microsoft office excel 2007.

\section{Results}

Initial data contained observation on phenotypic performance of 1216 pullets, which was finally adjusted to 1082 pullets belonging to 50 sire and 283 dam families. The data was adjusted for missing sire, dam, individual performance records and pullets laid less than 20 eggs or died before 40 weeks of age, by deleting from the initial record. The mean sum of squares from analysis of variance to test the hatch effects revealed significant difference between hatches for most of the traits. The least squares hatch corrected mean, SD, SE and $\mathrm{CV}$ for various traits have been presented in table 1 . The mean of EN-2 was found to be $67 \%$ of EN-1, which indicates that majority of eggs, was laid in early part of the day. SD and CV was more in EN-2 than EN-1. The mean value for MOT 40 and MOI 40 were $10.99 \mathrm{~h}$ and $24.34 \mathrm{~h}$ respectively. In spite of shorter recording period, 15 days MOT and MOI showed more variation in terms of SD and CV than MOT 40 and MOI 40. The reason may be more precise recording of oviposition time in half an hour intervals than one hour interval. In comparison to other traits, low values of SD and CV were observed in MOI which was expected because of the existence of $24 \mathrm{~h}$ barrier of light dark cycles (Yoo et al. 1986). The effect of selection over longer generations may have brought down the time to form an egg to around 24 hours. CV in all clutch traits was found to be more than the conventional as well as oviposition time traits.

The descriptive statistics of population mean for various traits have been shown in table 2 which indicates that ASM, EN-1, MOI, TCN, MCL, TPD and AIC have shown skewness and kurtosis of reasonable degree.

Large variation in range was observed for clutch traits. Highest range was observed for TPD and MCL. Frequency distributions of traits have been shown in fig 1 to 9. These figures show that within respective class intervals, pullets were not distributed uniformly. The distribution of EN-1 was more towards positive tail, indicating skewness of the population. More than $40 \%$ of the pullets were laying 120 to 135 eggs in EN-1. However, the distribution pattern of EN-2 was nearly normal, whereas, EN-3, EN-4 and EN-5 showed different patterns. From figure 2 to 5 , it can be observed that the distribution pattern of egg production is quite different for early (EN-2 and EN-3) and late period of the day (EN-4 and EN5). Majority of the birds (25\%) laying in the afternoon laid between 30 and 45 eggs, whereas, the majority (30\%) laying in the morning laid between 75 and 90 eggs. Therefore, a positive skewness would be expected for a frequency distribution of the morning layers, given that these are mainly the better layers, and vice versa with the afternoon distribution. In early period, higher percentage of pullets were laying higher number of eggs, where as lower percentage of pullets were laying lesser number of eggs in later part of the day. The distribution pattern of EN-1 with respect to ovipostion time was found to be nearly symmetrical (fig. 6) in $6 \mathrm{~h}-17 \mathrm{~h}$ of the day. From table 3, it is evident that $90 \%$ of ovipositions were completed before $13 \mathrm{~h}$ of the day. Mean oviposition time showed narrow range of distribution for both period of observation (fig. 6), however, comparatively more spread in distribution was observed for MOT 15 than MOT 40. Likewise MOI 40 and MOI 15 revealed very narrow range of distribution which led to peakedness of the distribution (fig.7). Distribution of flock for ACL and MCN was wider; however, deviation from normality was quite evident (fig. 8 and 9).

\section{Discussion}

Present study was planned to record the distribution pattern of different egg production traits, especially oviposition time, oviposition interval and clutch traits with the possibility to use them as selection criterion in further studies. To achieve this objective, various traits were recorded at $29^{\text {th }}$ generation of selection 
in a layer flock and distribution pattern was analyzed through population means, descriptive statistics and frequency distributions.

The mean values for BW 16, BW40, EW 28 and EW 40 were comparable to the reports of Chatterjee et al. (2008) but higher than Bais et al. (2007). Mean of ASM was comparable to the findings of Bais et al. (2007) but lower than Chatterjee et al. (2008). Differences in mean value from the reported literature might be attributed to the differences in number of generations of selection, selection criterion and genetic architecture of the populations.

The mean values for EN-1 was higher than the findings of Devi et al. (2005), Baise et al. (2007) and Chatterjee et al. (2008) which might be due to differences in generations at which means were reported and differences in population. The SD for ASM, EW and EN-1 were in accordance with the results of Lillpers and Wilhelmson (1993). EN-2 and EN-5 were comparable with the findings of Noda et al. (2002), whereas; EN-3 and EN-4 were not comparable because of unavailability of reports.

The oviposition of eggs in different time intervals of the day was studied with the assumption that early laying birds are good layers (Lillpers, 1991). The mean oviposition time was found to be about $05 \mathrm{~h}$ after the onset of light period and about $13 \mathrm{~h}$ from onset of darkness. The results are in agreement with the reports of Yoo et al. (1986) and Noddegaard (1998). However, it varied from the findings of Lillpers (1991) which might be due to the difference in duration of light-dark cycles and difference in onset of darkness.

The extent of variability (CV) was found to be least in ovulation interval (MOI 40 and MOI 15) whereas, more in various clutch traits (ACL, TCN, MCL, TPD and AIC). The cause of low variability in ovulation interval may be the long generations of selection and $24 \mathrm{~h}$ barrier of light- dark cycles (Yoo et al.1986). In addition, method of recording the ovulation interval in hourly intervals tends to reduce the spread of distribution. The spread of oviposition time and oviposition interval was more evident in half an hour than one hour intervals of recording. Mean and SD for oviposition intervals of this study were comparable to the findings of Sheldon et al. (1984) and Chen and Tixier-Biochard (2003 b).

The mean values for various clutch traits were in agreement with the observation of Johnston and Gous (2007). Similar results have been reported by Johnston and Gous (2007) for TCN, Bednarczyk et al. (2000) for ACL and Mc Clung et al. (1976) for AIC. However, Johnston and Gous (2007) have reported higher mean for MCL than the present study. The reason for difference in mean from the reported literature may be due to the method of measurement of different clutch traits, selection history and genetic architecture of the population. Internal ovulation, shell less eggs, soft shelled eggs, broken eggs and abnormally small eggs, if not counted in calculation of clutch length, then the ACL and MCL would decrease, whereas, TCN would increase.

It is normally assumed that in a large population, egg production traits follow normal distribution but often in long term selected population, traits deviate from normality as has been observed in figure 1 to 9 . Traits like clutch and oviposition interval often tends to deviate from normality (Lillpers and Wilhelmson, 1993 and Chen and Tixier-Biochard, 2003 b). Continued selection for egg number over many generations makes the population skewed and kurtotic, if extremes of high and low values are not excluded from the data before computation of mean. Skewness is a measure of symmetry, or more precisely the lack of symmetry. A data set is symmetric if it looks same at the left and right corner of distribution graph. Kurtosis is a measure of whether the data are peaked or flat relative to the normal distribution. Data sets with low kurtosis tend to have a flat top near the mean rather than a sharp peak. It is evident from table 2 that ASM, EN-1, MOI, TCN, MCL, TPD and AIC have shown skewness and kurtosis of reasonable degree. Literature also confirms the presence of skewness in these traits (Yoo et al. 1986, Lillpers, 1991, Luc et al. 1996, Chen and Tixier-Biochard, 2003 b), though of smaller magnitude than the present findings. Data were not transformed to follow normal distribution, as the purpose was to estimate the variability in traits within the existing population structure. Large variation in range of clutch traits was observed, which has also been reported by Johnson (2000) and Johnston and Gous (2007) in actual experimental populations.

The distribution patterns of different traits have been further shown in figure 1 to 9 , which repeats the deviation from normality. The pattern of distribution observed for EN-2 was similar to the findings of Noda et al. (2002). Similarly, the pattern observed for MOT, MOI and clutch traits were following the same trend as has been reported by Yoo et al.(1986) and Chen and Tixier-Biochard, (2003 b).

From present study, it becomes evident that EN-2 (early egg production) is having comparatively more variability than the traditional selection trait EN-1 and this trait may be utilized as principle trait either alone or in combination with other traits to improve the egg production further as has been demonstrated by Noda et al. (2002) through selection study. Similarly, oviposition time and average clutch length may become the potential trait to increase the egg production further due to greater variability than the traditional selection traits (Wolc et al. 2010). Further study on these traits in a large population is required with automated facility of recording oviposition time to validate these findings. Additional study on time dependent variations in layer traits would be useful in understanding the pattern of egg laying in a flock. 


\section{Acknowledgement}

The authors are thankful to the director, Defence Institute of High Altitude Research (DIHAR), Leh and all the supporting staffs of Experimental Layer Farm, CARI, Izatnagar.

\section{References}

[1] Anonymous (2007) in: Improvement of poultry for egg, QRT report (2001-06), PDP, Hyderabad (A.P.), India

[2] BACKHOUSE, D., GOUS, R.M. (2005) The effect of feeding time on shell quality and oviposition time in broiler breeders. British Poultry Science, 46(2): 255-259.

[3] BAIS, R.K.S., KATARIA, M.C., JOHARI, D.C., SHARMA, D., HAZARY, R.C., NISCHAL (2007) Performance evaluation and heterosis for economic traits of White Leghorn under reciprocal recurrent selection. Indian Journal of Poultry Science, 42(2): 131136.

[4] Bednarczyk, M., Kieclzewski, K., Szwaczkowski, T. (2000) Genetic parameters of the traditional selection traits and some clutch traits in a commercial line of laying hens. Archiv fur Geflugelkunde, 64(3): 129-133.

[5] Black, A. G., Ringer, R. K. (1987) Changes in ring -naked pheasants (Phasianus colenicus) egg formation time, oviposition lag time and egg sequence length due to light-dark cycles. Poultry Science, 66: 231-236.

[6] Carlborg, O., Jacobson, L., Ahgren, P., Siegel, P., Anderson, L. (2006) Epistasis and the release of genetic variation during long-term selection. Nature Genetics, 38: 418-420.

[7] Chatterjee, R.N., Niranjan, M., A.K., Reddy, B.L.N., Bhanja, S.K., Singh, D (2008) Inheritance of important economic traits in 3 pure lines and a control population of white leghorn. Indian Journal of Animal Science, 78(1): 75-79.

[8] Chen, C.F., Tixier-Biochard, M. (2003 a) Correlated response to long term selection for clutch length in dwarf brown -egg layers or not carrying the naked neck gene. Poultry Science, 82: 709-720.

[9] Chen, C.F., Tixier-Biochard, M. (2003 b) Estimation of genetic variability and selection response for clutch length in dwarf brownegg layers carrying or not the naked neck gene. Genetic selection Evolution, 35: 219-238.

[10] Devi, K.S., Reddy, P.M. (2005) Genetic studies on certain economic traits in White Leghorn and cross-bred chicken. Indian Journal of Poultry Science, 40(1): 56-58.

[11] Figueiredo, E. A. P., Schmidt, G.S., Ledur, M.C., Rosa, P.S. (2000) Correlation between oviposition and productive traits in White Leghorn strains. British Poultry Science, 41: 26: 33.

[12] Harvey,W.R. (1990) User's Guide for LSMLMW and MIXMDL PC-2 Version. Colombus, Ohio.

[13] Johnson, A.L. (2000) in: Sturkie's Avian Physiology, 'Ovulation-Oviposition cycle and rate of lay', Pages 575-576, G. Causey Whittow, $5^{\text {th }}$ ed. Academic Press.

[14] Johnston, S.A., Gous, R.M. (2007c) Extent of variation within a laying flock: attainment of sexual maturity, double-yolked and softshelled eggs, sequence lengths and consistency of lay. British Poultry Science, 48(5): 609-616.

[15] Lewis, P.D., Ciacciariello, M., Ciccone, NA., Sharp, P.J., Gous., R.M.(2005) Lighting regimnes and Plasma LH and FSH in broiler breeders. British Poultry Science, 46 (3)349-353.

[16] Lillpers, K. (1991) Genetic variation in the time of oviposition in the laying hen. British Poultry Science, 32(2): 303-312.

[17] Lillpers, K., Wilhelmson, M. (1993) Genetic and phenotypic parameters for oviposition pattern traits in three selection lines of laying hens. British Poultry Science, 34(2): 297-308.

[18] Luc, K.M., Miyoshi, S., Kuchida, K., Mitsumoto, T. (1996) Comparison of the clutch traits and egg production predicted by the multiphasic model among the laying strains. Japanese Poultry Science, 33(4): 235-241.

[19] Mc Clung, M.R., Wang, A.B.S., Jones, W.T. (1976) Heritability estimates of some clutch traits in laying hens. Japanese Poultry Science, 33: 23-28.

[20] Noda, K., Kino, K., Miyakawa, H., Banba, H., Umezawa, Y. (2002) Persistency of laying strain building by index selection including oviposition time as selection trait in laying hen. Journal of Poultry Science, 39(3):140-148

[21] Noddegaard, F. (1998) Oviposition patterns and plasma melatonin rhythms in response to manipulations of the light:dark cycle. British Poultry Science, 39: 653-661.

[22] Osborne, R. (1957a) The use of sire and dam family averages in increasing the efficiency of selective breeding under a hierarchical mating system. Heredity, 11: 93-116.

[23] Osborne, R. (1957b) Family selection in Poultry. The use of sire and dam family averages in choosing male parents. Proc. Roy. Soc. Edinburgh, B66: 374-393.

[24] Patterson, P.H. (1997) The relationship of oviposition time and egg characteristics to the daily light: dark cycle. Journal of Applied Poultry Research, 6: 381-390.

[25] Pavlidis, H. O., Price, S.E., Siegel, P.B. (2002) Associations between egg production and clutch length in four selected lines of chickens. Journal of Applied Poultry Research, 11(3): 304-307.

[26] Sheldon, B.L., Yoo, B.H., Podger, R.N. (1984) Increasing egg yield under normal light cycles by selecting for short interval between eggs under continuous light. Annales Agriculturae Fenniae, 23(4): 216-225.

[27] Siegel. P.B., Dodgson, J.B., Andersson, L. (2006) Progress from chicken genetics to the chicken genome. Poultry Science, 85: 20502060.

[28] Wolc, A., Bednarczyk, M., Lisowski, M., Szwaczkowski, T.(2010) Genetic relationships among time of egg formation, clutch traits and traditional selection traits in laying hens. Journal of Animal and Feed Science, 19: 452-459.

[29] Yoo, B.H., Sheldon, B.L., Podger, R.N. (1986) Analyses of oviposition times and intervals in a wide range of layer flocks under normal and continuous lighting regimes. British Poultry Science, 27(2): 267-287.

[30] Zakaria, A.H., Plumstead, P.W., Romero-Sanchez, H., Leksrisompong, N., Osborne, J., Braket, J. (2005) Oviposition pattern, egg weight, fertility, and hatchability of young and old broiler breeders. Poultry Science, 84: 1505-1509. 
Study Of Oviposition Pattern And Clutch Traits In A White Leghorn (WL) Layer Population'

Table1. Least squares means of hatch corrected data for various Layer traits

\begin{tabular}{|c|c|c|c|c|c|c|}
\hline Sl. No. & Traits & Unit & Mean & S.D. & S.E. & $\%$ C.V. \\
\hline 1 & BW 16 & $\mathrm{gm}$ & 863.49 & 97.70 & 2.97 & 11.31 \\
\hline 2 & BW 40 & $\mathrm{gm}$ & 1436.24 & 154.91 & 4.71 & 10.79 \\
\hline 3 & EW 28 & $\mathrm{gm}$ & 45.91 & 2.81 & 0.09 & 6.11 \\
\hline 4 & EW 40 & $\mathrm{gm}$ & 53.10 & 2.62 & 0.08 & 4.94 \\
\hline 5 & ASM & Days & 140.35 & 10.97 & 0.33 & 7.82 \\
\hline 6 & EN-1 & Eggs & 116.98 & 23.90 & 0.73 & 20.43 \\
\hline 7 & EN-2 & Eggs & 78.29 & 27.48 & 0.84 & 35.10 \\
\hline 8 & EN-3 & Eggs & 95.01 & 25.93 & 0.79 & 27.29 \\
\hline 9 & EN-4 & Eggs & 26.51 & 15.05 & 0.46 & 56.76 \\
\hline 10 & EN-5 & Eggs & 37.71 & 20.46 & 0.62 & 54.27 \\
\hline 11 & MOT 40 & $\mathrm{~h}$ & 10.99 & 0.76 & 0.02 & 6.89 \\
\hline 12 & MOT 15 & $\mathrm{~h}$ & 10.70 & 1.23 & 0.04 & 11.53 \\
\hline 13 & MOI 40 & $\mathrm{~h}$ & 24.34 & 0.34 & 0.01 & 1.39 \\
\hline 14 & MOI 15 & $\mathrm{~h}$ & 24.43 & 0.60 & 0.02 & 2.46 \\
\hline 15 & ACL & Days & 11.10 & 6.57 & 0.20 & 59.20 \\
\hline 16 & $\mathrm{TCN}$ & Clutch & 12.69 & 5.15 & 0.16 & 40.57 \\
\hline 17 & MCL & Days & 38.15 & 21.66 & 0.66 & 56.76 \\
\hline 18 & TPD & Days & 23.67 & 22.16 & 0.67 & 93.60 \\
\hline 19 & AIC & Days & 2.20 & 3.63 & 0.11 & 164.76 \\
\hline \multicolumn{7}{|c|}{ Table 2. Descriptive Statistics of Population Means } \\
\hline Sl. No. & Traits & Skewness & Kurtosis & Median & Maximum & Minimum \\
\hline 1 & BW 16 & -0.03 & 0.17 & 850.00 & 1200.00 & 500.00 \\
\hline 2 & BW 40 & 0.25 & 0.95 & 1438.50 & 2000.00 & 800.00 \\
\hline 3 & EW 28 & 0.01 & 0.41 & 46.03 & 56.47 & 35.90 \\
\hline 4 & EW 40 & 0.02 & 0.07 & 53.03 & 63.00 & 42.00 \\
\hline 5 & ASM & 0.75 & 1.16 & 140.00 & 185.00 & 114.00 \\
\hline 6 & EN-1 & -2.05 & 4.44 & 123.00 & 153.00 & 20.00 \\
\hline 7 & EN-2 & -0.17 & -0.45 & 78.00 & 148.00 & 6.00 \\
\hline 8 & EN-3 & -0.87 & 0.67 & 99.00 & 148.00 & 9.00 \\
\hline 9 & EN-4 & 0.50 & -0.05 & 26.00 & 79.00 & 1.00 \\
\hline 10 & EN-5 & 0.37 & -0.26 & 37.00 & 109.00 & 1.00 \\
\hline 11 & MOT 40 & -0.22 & 0.21 & 11.05 & 13.73 & 8.39 \\
\hline 12 & MOT 15 & -0.07 & -0.12 & 10.71 & 15.46 & 7.13 \\
\hline 13 & MOI 40 & 3.27 & 16.69 & 24.18 & 30.00 & 23.64 \\
\hline 14 & MOI 15 & 2.59 & 10.29 & 24.24 & 26.71 & 23.75 \\
\hline 15 & ACL & 0.78 & 0.77 & 12.00 & 36.00 & 2.00 \\
\hline 16 & $\mathrm{TCN}$ & 2.81 & 14.50 & 9.84 & 66.00 & 1.54 \\
\hline 17 & MCL & 1.22 & 1.77 & 33.00 & 131.00 & 5.00 \\
\hline 18 & TPD & 2.66 & 7.29 & 17.00 & 130.00 & 1.00 \\
\hline 19 & AIC & 7.09 & 72.69 & 1.24 & 58.00 & 0.45 \\
\hline
\end{tabular}

Table 3. Distribution of egg production (\%) with respect to oviposition time

\begin{tabular}{ccc}
\hline Oviposition Time $(\mathrm{h})$ & Percentage production & $\begin{array}{c}\text { Cummulative } \\
\text { percentage production }\end{array}$ \\
\hline 06.00 & 0.73 & 0.73 \\
07.00 & 1.78 & 2.51 \\
08.00 & 3.88 & 6.39 \\
09.00 & 14.31 & 20.70 \\
10.00 & 24.53 & 45.24 \\
11.00 & 21.92 & 67.16 \\
12.00 & 14.54 & 81.70 \\
13.00 & 8.52 & 90.23 \\
15.00 & 7.75 & 97.99 \\
17.00 & 2.00 & 99.99 \\
\hline
\end{tabular}




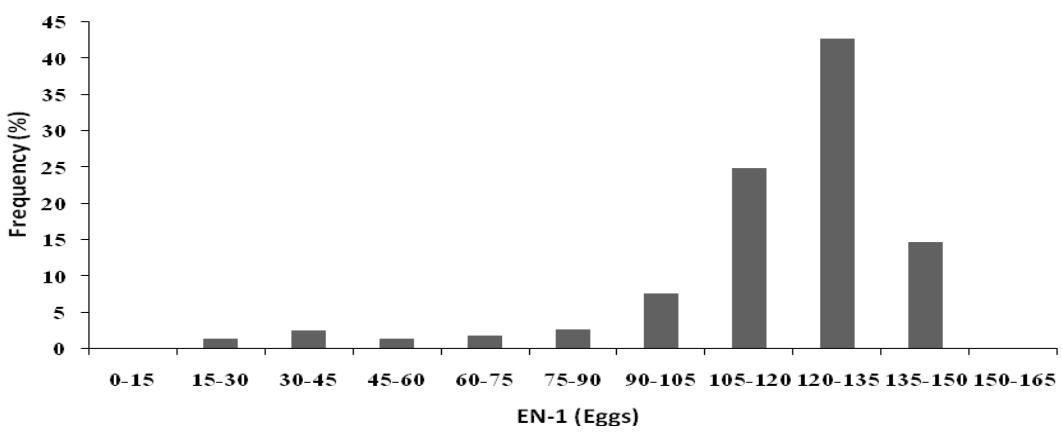

Figure 1. Frequency distribution of EN-1

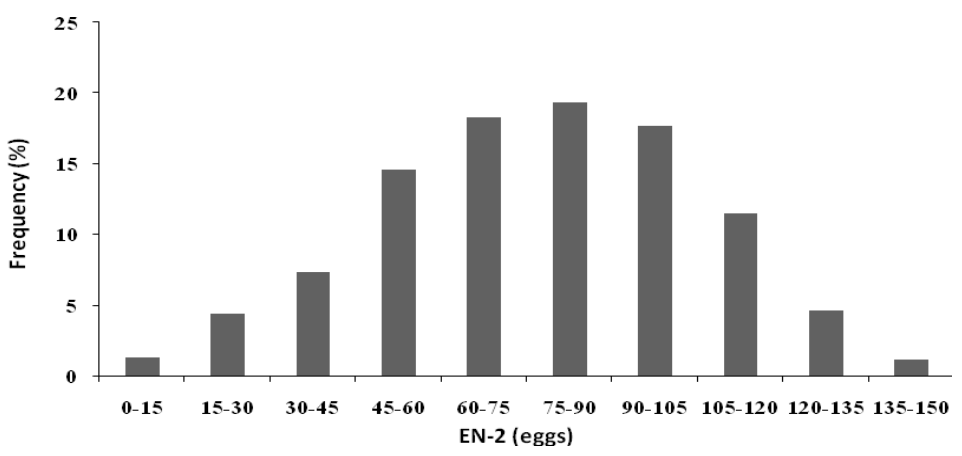

Figure 2. Frequency distribution of EN-2

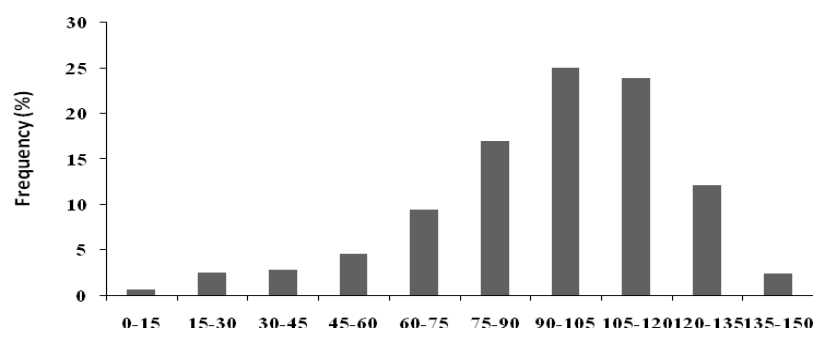

Figure 3. Frequency distribution of EN-3

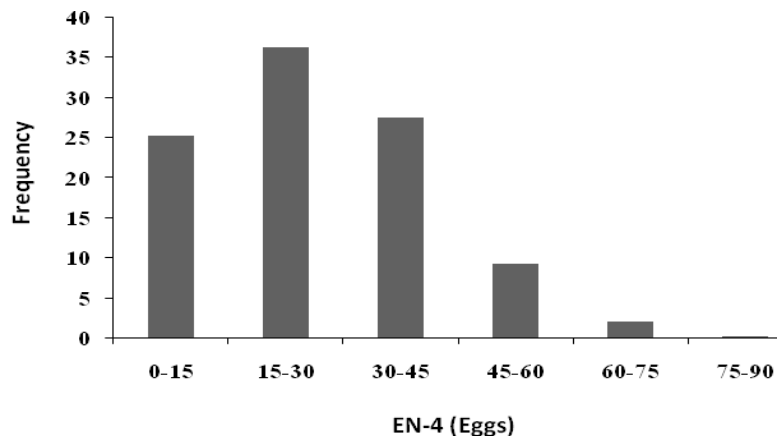

Figure 4. Frequency distribution of EN-4 


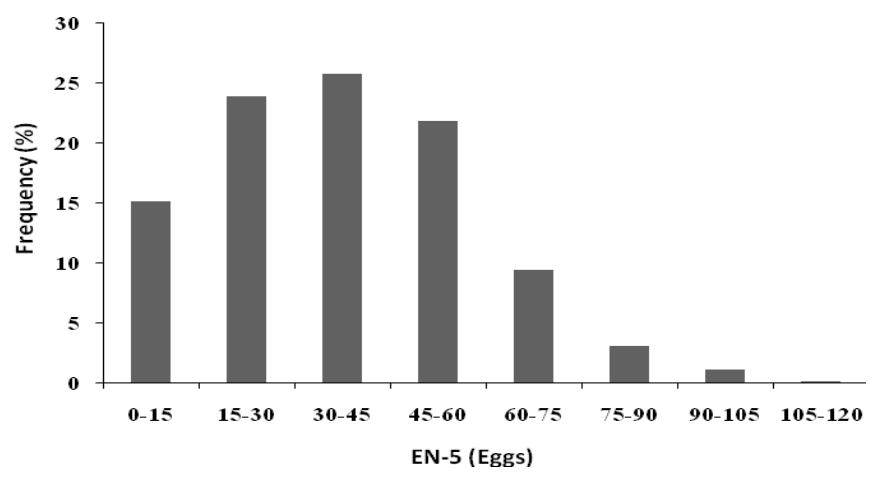

Figure 5. Frequency distribution of EN-5

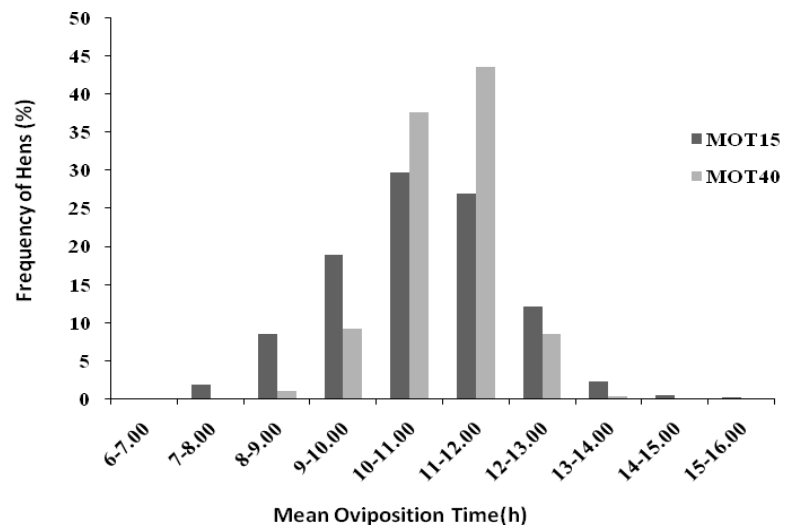

Figure 6. Frequency distribution of Mean ovipositon time (MOT)

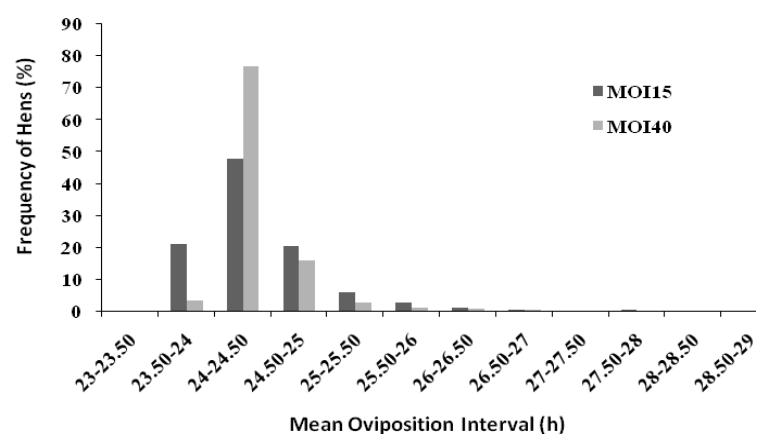

Figure 7. Frequency distribution of Mean oviposition interval (MOI) 


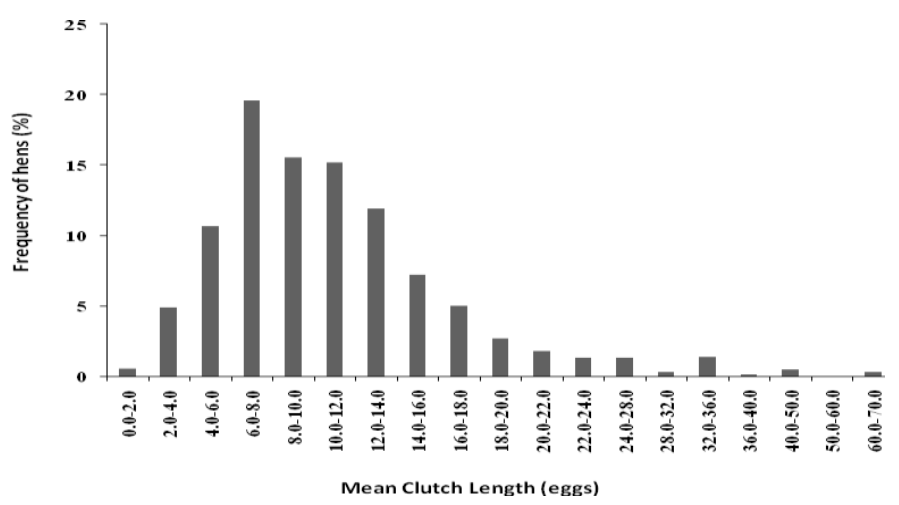

Figure 8. Frequency distribution of Clutch length (MCL)

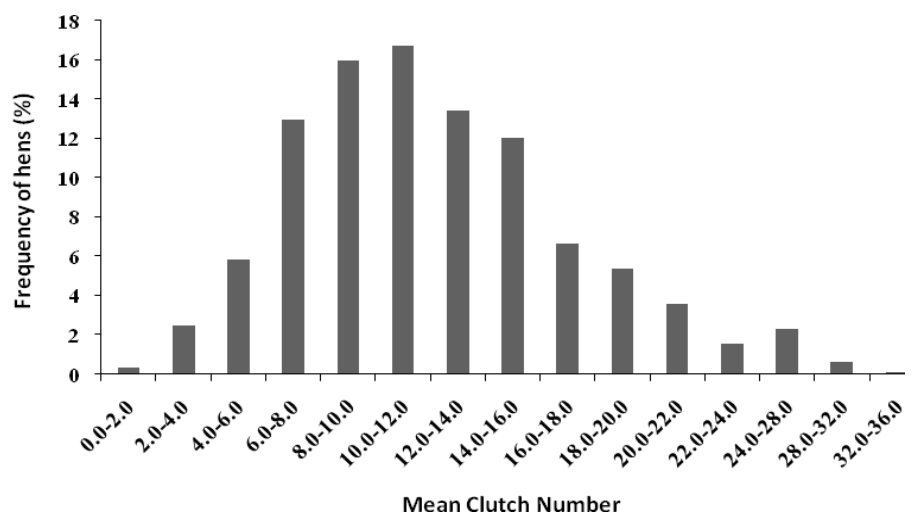

Figure 9. Frequency distribution of Average Clutch number (ACL) 